\title{
Algorithm Synthesis of Controlling a Transport Unit of a Coextrusion Flexible Manufacturing Section for Processing Multicomponent Materials
}

\author{
Valery V. Dyadichev ${ }^{1, a^{*}}$, Sergey S. Stoyanchenko ${ }^{2, b}$, Roman L. Plomodyalo ${ }^{3, c}$ and \\ Aleksandr V. Dyadichev ${ }^{1, d}$ \\ ${ }^{1}$ V.I. Vernadsky Crimean Federal University, 2 Pavlenko Street, Simferopol, Russia \\ ${ }^{2}$ Lugansk State University named after Vladimir Dal, 20-A Molodezhnyi Sq., Lugansk, Ukraine \\ ${ }^{3}$ Kuban State Technological University (KubSTU), Moskovskaya str. 2, Krasnodar, Russia \\ amr.dyadichev@mail.ru, ${ }^{\mathrm{b}}$ santono@mail.ru, ${ }^{\mathrm{c}}$ ndt-2018@mail.ru, ${ }^{\mathrm{d}}$ adyadichev@mail.ru
}

Keywords: Algorithm, Mixture of Materials, Dosing Device, Multicomponent Materials, Synthesis, Coextrusion Manufacturing Section

\begin{abstract}
The paper offers a mathematical model of the process of coextrusion flexible manufacturing section functioning. On the basis of dynamic programming method an algorithm of controlling transport unit of coextrusion flexible manufacturing system is developed. The objective of the current research is the development of the mathematical model of the flexible manufacturing complex for processing multicomponent materials functioning process, and construction of the algorithm of controlling a transport unit of a coextrusion flexible manufacturing complex for processing multicomponent materials on this basis. The paper offers the criterion of evaluating the quality of controlling the transport unit. The chosen variant of controlling the transport unit has to meet many requirements. This paper con-siders the issues connected with the search for an optimum algorithm of control-ling a transport unit according to the set criterion. Most works offer analytical models which are based on the assumption of the current processes' stability. Real manufacturing conditions are characterized by the effect of numerous perturbing factors. Under such conditions the assumption of the current processes' stability makes the obtained models almost untrue.
\end{abstract}

\section{Introduction}

Using the automation of transport work in the GPS allows eliminating the hard work of auxiliary workers and freeing them to participate in the main process, saves time for the main workers, who spend up to $20 \%$ of the total fund of time on the receipt and delivery of blanks, parts, equipment.

Upon the arrival of goods to the GPS, after work on a batch of parts completion, the vehicles are the main executive devices that implement control algorithms for the transfer of goods in the system. Cargo flows in the GPS are extremely diverse - these are billets, semi-finished products, finished parts, equipment, production waste. Universal vehicles can be used for these material flows, but separate transport subsystems are often used [1-6].

The interconnection of transport in the GPS with the control system, storage devices for the elements of the material flow, various design solutions are significantly complicate the tasks of developing a transportation system of GPS. For type site as GPS we can distinguish non-systemic, interoperational and operational transport. Non-systemic transport provides the connection of the GPS with other production units, and above all with a higher-level system, which is responsible for providing the GPS with blanks and equipment, determines the further movement of finished

(c) (i) Content from this work may be used under the terms of the Creative Commons Attribution 3.0 license. Any further distribution of this work must maintain attribution to the author(s) and the title of the work, journal citation and DOI. Published under license by Materials Research Forum LLC. 
parts to the consumer, ensures the delivery of cutting tools and other equipment. The role of offsystem transport varies depending on the degree of independence of the GPS. The organization of retrieval system work determines greatly the work efficiency of the flexible manufacturing section. The efficiency of separate units of the techno-logical equipment very often differs considerably. The only transport unit quite often operates several units of the technological equipment. Under such conditions the solution to the problem of controlling the transport unit of the production complex is of a peculiar difficulty. The chosen variant of control-ling the transport unit has to meet many requirements. This paper considers the issues connected with the search for an optimum algorithm of controlling a transport unit according to the set criterion.

\section{Analysis of Scientific Publications}

Many scientific researches [7-17] are dedicated to scrutinizing the issues of mathematic modelling of multifunctional manufacturing systems. The scientific work studies the issues of analyzing the structures of the traffic in flexible manufacturing systems. Most works offer analytical models which are based on the assumption of the current processes' stability. Real manufacturing conditions are characterized by the effect of numerous perturbing factors. Under such conditions the assumption of the current processes' stability makes the obtained models almost untrue.

\section{The Objective of the Work}

The objective of the current research is the development of the mathematical model of the flexible manufacturing complex functioning process, and construction of the algorithm of controlling a transport unit of a flexible manufacturing complex on this basis. The paper offers the criterion of evaluating the quality of controlling the transport unit.

\section{Research}

While developing technological structures of manufacturing systems, they often use the variant when one transport unit serves several technological modules (see Fig. 1). Under wrong management of the work by the transport unit downtimes of technological modules may happen due to the absence of workpieces and too often rearrangements of the transport unit. In such systems it is necessary to manage the work of the transport unit in order to prevent or minimize the downtimes of technological modules and minimize the amount of rearrangements of the transport units. The analysis of the task of search for a rational strategy of controlling the transport unit shows that this task belongs to the class of dynamic tasks of discreet optimization [18-20].

To formulate the task of search for a strategy of controlling the transport unit in terms of dynamic programming we will introduce a range of hypotheses. Let the average time of transporting be equal to all the technological sections and be $t$ time units. The duration of the transport unit arrangement for serving $i$ technological module is Tai time units. We will designate by tai the number showing how much Tai is bigger than t. Let also ti be the number showing how many times an average duration of the cycle $i$ of the technological module is bigger than $t$. Let us designate by Ei the piece capacity of the input for i module of the storage ( $I=1, M, M$ is the amount of the technological modules, served by the transport unit).

Let us consider the functioning process of the flexible manufacturing section at the time interval from 0 to $\mathrm{T}$ and divide it into a range of pieces $\Delta t$. The duration of each piece equals to the duration of the transport operation.

The control over the transport unit will be set in a form of a vector $X$, the dimension of which equals to the amount $\mathrm{K}$ of pieces, into which the considered interval is divided $0 . . T$. The elements $X_{j} \mathrm{j}=1, \mathrm{~K}$ of this vector reflect taking a definite decision at a corresponding piece $\Delta t$, the decision 
concerns the control over the transport unit. Let us assume that $X_{j}$ equals to $l$, then it means that at $j$-piece one of the possible decisions concerning the control over the transport unit was taken:

$$
\begin{aligned}
& 1 \leq l \leq M-\quad \text { is the transportation at j-piece of one manufactured item for } l \text {-section; } \\
& (M+1) \leq l \leq 2 \cdot M \quad \text { - is the downtime of the transport unit, arranged for transportation of items }
\end{aligned}
$$
for (1-M) technological module;

$(2 \cdot M+1 \leq l \leq 3 \cdot M$ - is the rearrangement of the transport unit for transporting items for ( $l$ $2 M)$ technological module.

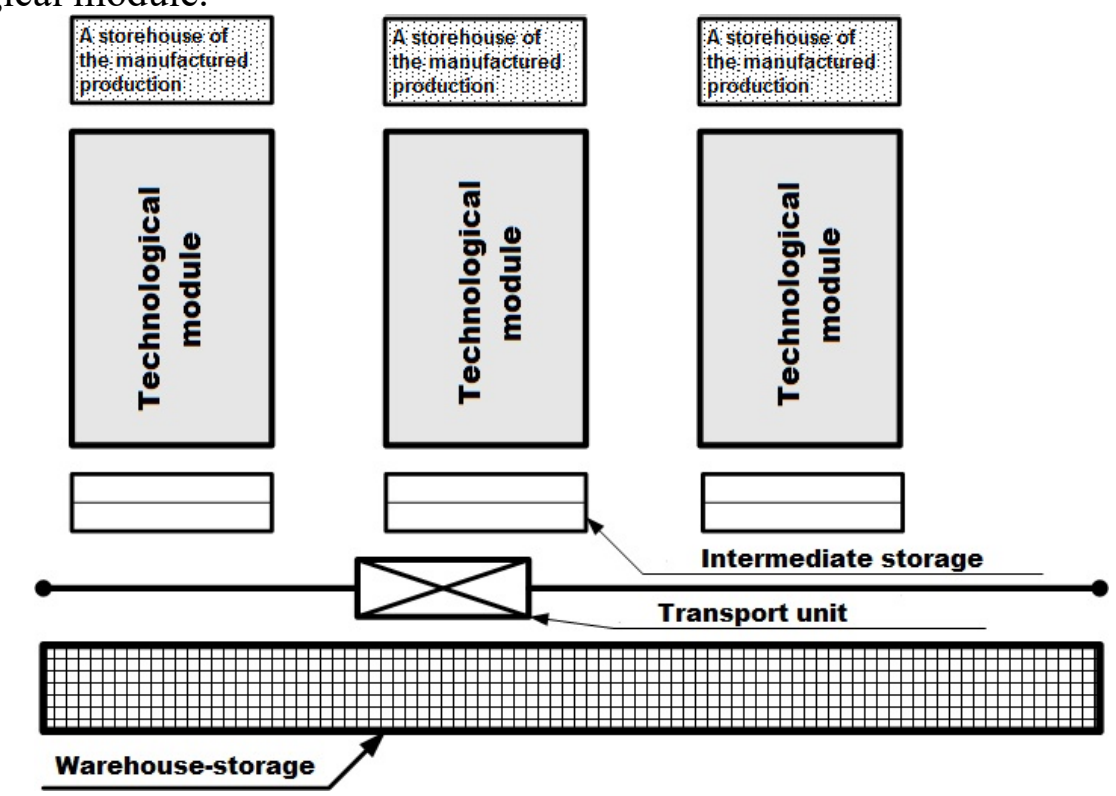

Fig. 1. The scheme of a flexible manufacturing section with a common transport unit

The space of states, in which the studied system may be at each step, is described by the group of three $<\mathrm{A}, \mathrm{B}, \mathrm{C}>$. Here $\mathrm{A}$ is the number of the technological module, at the items' transportation of which the transport unit is arranged $(1 \leq \mathrm{A} \leq \mathrm{M})$. $\mathrm{B}$ and $\mathrm{C}$ are the vectors of the dimension $\mathrm{M}$. Each component bi $(\mathrm{I}=1, \mathrm{M})$ of the vector $\mathrm{B}$ numerically equals to the amount of the manufactured items, contained in the input for $\mathrm{i}$-section storage $\left(0 \leq \mathrm{b}_{\mathrm{i}} \leq \mathrm{E}_{\mathrm{i}}\right)$. The component ci $(i=1, M)$ of the vector $\mathrm{C}$ shows how many steps (pieces) are left to the delivery of the signal by i-technological module for the supply of the next item $\left(0 \leq \mathrm{c}_{\mathrm{i}} \leq \mathrm{t}_{\mathrm{i}}\right)$ to this module. The general number of states in which the system may be at each step is determined by the next expression:

$$
M \cdot \prod_{i=1}^{M}\left(\left(E_{i}+1\right) \cdot\left(t_{i}+1\right)\right)
$$

The common costs $F$, connected with the operation of the flexible manufacturing complex, can be presented as a sum:

$$
\mathrm{F}=\mathrm{F} 1+\mathrm{F} 2
$$

Here F1 is the losses determined by the downtimes of the technological modules:

$$
F_{1}=\sum_{i=1}^{M} e_{i} \sum_{j=1}^{k} q_{i j}
$$

where:

$$
q_{i j}=1 \text {, if } b_{i j}+c_{i j}=0 \text {, }
$$


0 , if not,

$e_{i}-$ is the cost connected with the downtime of i-technological module during one piece $\Delta t$.

$\mathrm{F}_{2}$ is the losses connected with the rearrangement of the transport unit

$F_{2}=e_{p} \sum_{j=1}^{k} r_{j}$

where $r_{j}-1$, if $x_{j} \leq 2 M$ and $x j+1>2 M$,

0 - if not.

In multistep processes with a subsequent decision taking the transition of the system from one step to another and from one state to another is described by a functional equation. For the considered task the functional equation of the dynamic programming is presented as follows:

$$
F_{k}(s)=\min _{\substack{s \in S \\ s \in S}}\left[g_{k}(s)+F_{k-l}\left(s^{\prime}\right)\right]
$$

where: $\mathrm{S}$,

$F_{k}(\mathrm{~s})$ is the value of the target function (1), obtained at the step $\mathrm{k}$ of the optimization to the state

$g_{k}(\mathrm{~s})$ is the increment of the target function under the transition of the manufacturing system form the state s' at $(k-l)$-step in to the state s at k-step,

$S^{\prime}$ is the multitude of states at $(k-l)$-step, from which the transition into the state $\mathrm{S}$ at k-step is possible,

$S$ is the multitude of possible states of the manufacturing system at each step.

$l$ is tai, if in the state $\mathrm{s}$ of the manufacturing system the transition is performed by the rearrangement of the transport unit for transporting the manufactured items for $\mathrm{i}$ technological module,

1 if not.

Fig. 2 shows the work scheme of the obtained method of algorithm synthesis of controlling the transport unit of the flexible manufacturing complex.

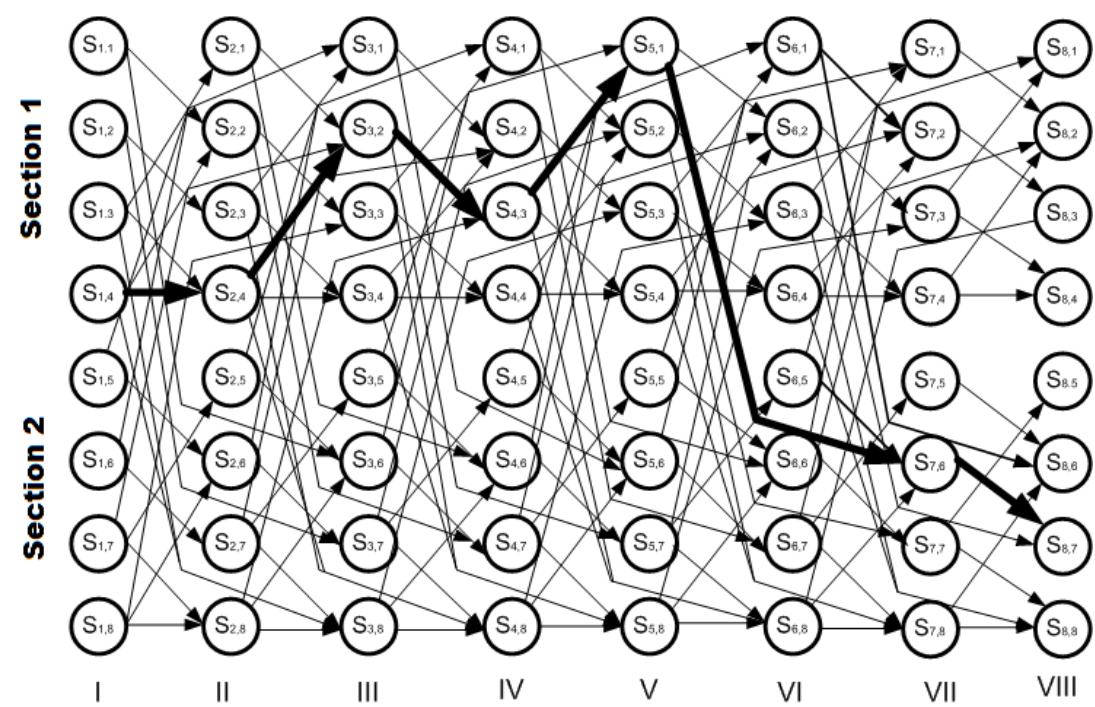

Fig. 2. The work scheme of the dynamic programming algorithm for searching a strategy for controlling the transport unit 
The calculating experiments with the computer implementation of the obtained algorithm of controlling the transport unit showed that its use reduces the losses connected with the operation of the flexible manufacturing complex by $25-20 \%$. It is necessary to mention specially that the developed algorithm has a high performance. This fact allows using it in such manufacturing systems where the manufacturing tasks are often changed.

Displayed equations are centered and set on a separate line.

$$
x+y=z
$$

\section{Acknowledgement}

The study was carried out with the financial support of the Ministry of Education and Science of the Russian Federation within the framework of the scientific project FZEG-2020-0030.

\section{References}

[1] B. Bauer, R.F. Bullnheimer, C. Hartl, Strauss. Minimizing total tardiness on a single machine using ant colony optimization, Proc. of the 1999 Congress on Evolutionary Computation (CEC99), Washington D.C., USA (1999) 1445-1450

[2] J. Blazewicz, et all, Handbook on Scheduling. From Theory to Practice, Springer Verlag (2019). https://doi.org/10.1007/978-3-319-99849-7

[3] O. Brucker, Scheduling Algorithms. Springer Verlag (2007)

[4] P. Brucker, S. Kravchenko, Scheduling Jobs With Release times on Parallel Machines to Minimize Total Tardiness. OSM Reihe P, Heft 258, Universit ä Osnabr ück, Fachbereich Mathematik/ Informatik (2005)

[5] S. Chang, Q. Lu, G. Tang, W. Yu, On decomposition of total tardiness problem, Oper. Res. Lett. 17 (1995) 221-229. https://doi.org/10.1016/0167-6377(95)00027-H

[6] F. Della, A. Croce, V. Grosso, Paschos, lower bounds on the approximation ratios of leadingheuristics for the single-machine total tardiness problem, J. of Scheduling 7 (2004) 85-91. https://doi.org/10.1023/B:JOSH.0000013056.09936.fd

[7] A.P. Gavrish, B.M. Voronets, Robotized Machine Building Construction Complexes for Mechanical Processing (in Russian), Technika, Kyev (1984)

[8] E.N. Khobotov, Some models and solution methods for scheduling tasks in discrete manufacturing systems, A\&T 12 (2007)85-100

[9] I.A. Klausov, I.S. Blyakherov, G.M Varyash, A.A. Ivanov, Automatic Loading of Technological Machines (in Russian), Reference book, Mashinostroyeniye, Moscow (1990)

[10] M.S. Kunyaev, A.M. Sidorenko, A.S. Firsov, E.N. Khobotov, Methods of schedule building in manufacturing systems, MSTU named after N.E. Bauman (2009)

[11] A. Lazarev, A. Kvaratskhelia, Tchernykh, Solution algorithms for the total tardiness scheduling problem on a single machine, Workshop Proc. of the ENC'04 Int. Conf. (2004) 474480

[12] D. Merkle, M. Middendorf, An Ant Algorithm with a New Pheromone Evaluation Rule for Total Tardiness Problem, Evo Work Shops, LNCS 1803, Springer, Verlag (2000) 287-296. https://doi.org/10.1007/3-540-45561-2_28

[13] M.L. Pinedo, Planning and Scheduling in Manufacturing and Services, Springer Dordrecht Heidelberg ,London, New York (2009). https://doi.org/10.1007/978-1-4419-0910-7 
[14] M.L. Pinedo, Scheduling. Theory, Algorithms, and Systems, Springer, Dordrecht Heidelberg London, New York (2008)

[15] K. Rikhter, Dynamic problems of discrete optimization (in Russian), Radio and communication, Moscow (1985)

[16] C. Schwindt, et al., Handbook on Project Management and Scheduling 1, Springer International Publishing, Berlin, Heidelberg, New York (2015). https://doi.org/10.1007/978-3319-05443-8

[17] A.M. Sidorenko, E.N. Khobotob, An aggregation in scheduling on machine building enterprises, Control theory and systems 5 (2013) 132-144.

https://doi.org/10.1134/S1064230713050110

[18] Z. Tian, C.T. Ng, T.C.E. Cheng, An O(n2) algorithm for scheduling equal-length preemptive jobs on a single machine to minimze total tardiness, J. of Scheduling 9(4) (2006) 343-364. https://doi.org/10.1007/s10951-006-7039-6

[19] W. Szwarc, A. Grosso, F. Della Croce, Algorithmic paradoxes of the single machine totaltardiness problem, J. of Scheduling 4 (2001) 93-104. https://doi.org/10.1002/jos.69

[20] V.A. Yegorov, V.D. Lusanov, S.M. Scherbakov, Transporting Storing Systems. FMS (in Russian), Mashinostroyeniye, Leningrad (1989) 